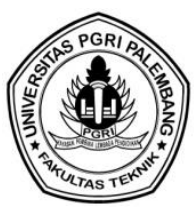

\title{
PENGARUH CANGKANG KERANG SEBAGAI SUBSTITUSI AGREGAT KASAR DENGAN BAHAN TAMBAH SUPERPLASTICIZER PADA KUAT TEKAN BETON
}

\author{
Lina Flaviana Tilik, Fadhila Firdausa*, Muhammad Rifqi Agusri, Puji Hartoyo \\ Jurusan Teknik Sipil, Politeknik Negeri Sriwijaya \\ "Corresponding Author, Email : fadhilafirdausa@polsri.ac.id
}

\begin{abstract}
ABSTRAK
Beton adalah bahan konstruksi yang diperoleh dari pencampuran pasir, kerikil, atau batu hancur, semen, dan air. Untuk meningkatkan sifat beton, beberapa jenis aditif yang memiliki fungsi tertentu ditambahkan ke campuran beton, yaitu meningkatkan kemampuan kerja, daya tahan, dan waktu pengerasan beton. Kerang dengan kualitas dan bentuk yang sangat baik digunakan sebagai bahan kerajinan, sedangkan bentuk yang buruk dapat menyebabkan limbah yang mengakibatkan serangkaian masalah lain, terutama kebersihan lingkungan sekitarnya. Penelitian ini bertujuan untuk menentukan efek kerang sebagai substitusi agregat kasar dengan bahan tambahan superplasticizer pada kekuatan tekan beton. Spesimen yang digunakan adalah silinder dengan diameter $15 \mathrm{~cm}$ dan tinggi $30 \mathrm{~cm}$. Komposisi kerang yang ditentukan dalam penelitian ini adalah 0\%, 5\%, 10\%, 15\%, 20\% dan 0,5\% superplasticizer ditambahkan. Kualitas beton yang direncanakan adalah $F c=25 M P a$. Nilai kekuatan tekan beton meningkat dengan penambahan cangkang sebesar 5\% dan menurun dalam penambahan cangkang di atas 5\% dengan superplasticizer 0,5\% ditambahkan. Kekuatan tekan beton normal dan beton superplastisizer 0,5\% adalah 28,26 MPa dan 29,15 MPa pada usia 28 hari dan kekuatan tekan beton shell dengan komposisi 5\%, 10\%, 15\%, dan 20\% ditambahkan dengan superplasticizer 0,5\% menghasilkan kekuatan tekan 30,78MPa; 26.78MPa; 24,71 $\mathrm{MPa}$, dan 22,93 MPa pada usia 28 hari.
\end{abstract}

Kata Kunci : Kuat Tekan; Cangkang Kerang Darah; Superplasticizer

\begin{abstract}
Concrete is a construction material obtained from mixing sand, gravel, or crushed stone, cement, and water. To improve the properties of concrete, several kinds of additives that have certain functions are added to the concrete mixture, namely increasing the workability, durability, and hardening time of the concrete. Shells with excellent quality and shape are used as craft materials, while bad shapes can cause waste which results in a series of other problems, especially the cleanliness of the surrounding environment. This study aims to determine the effect of shells as a substitution of coarse aggregate with superplasticizer added material on the compressive strength of concrete. The specimens used were cylindrical with a diameter of $15 \mathrm{~cm}$ and a height of $30 \mathrm{~cm}$. The composition of the shells determined in this study was $0 \%, 5 \%, 10 \%, 15 \%, 20 \%$ and $0.5 \%$ superplasticizer added. The planned concrete quality is $\mathrm{Fc}=25 \mathrm{MPa}$. The value of the compressive strength of concrete increased with the addition of shells by 5\% and decreased in the addition of shells above 5\% with $0.5 \%$ superplasticizer added. The compressive strength of normal concrete and $0.5 \%$ superplasticizer concrete is $28.26 \mathrm{MPa}$ and $29.15 \mathrm{MPa}$ at the age of 28 days and the compressive strength of shell concrete with a composition of 5\%,10\%, 15\%, and $20 \%$ added with superplasticizer 0,5\% produces a compressive strength of $30.78 \mathrm{MPa} ; 26.78 \mathrm{MPa} ; 24.71 \mathrm{MPa}$, and $22.93 \mathrm{MPa}$ at the age of 28 days.
\end{abstract}

Keywords : Compressive Strength; Blood Clam Shell; Superplasticizer

\section{PENDAHULUAN}

Semakin berkembangnya pembangunan dan meningkatnya populasi manusia yang sangat pesat, mengakibatkan bahan material beton semakin berkurang. Oleh karena itu berbagai penelitian dan percobaan tentang material beton telah dilakukan guna mencari 
bahan lain sebagai penunjang bahan material beton dan juga ramah terhadap lingkungan. Beton adalah seperangkat interaksi mekanik dan kimia dari bahan penyusun dan memenuhi kekuatan batas yang diperlukan oleh perencana dan memenuhi kemampuan servis yang juga dapat diartikan sebagai layanan yang andal dengan memenuhi kriteria ekonomi.(Mulyono 2005)

Indonesia merupakan negara kepulauan, dengan luas wilayah perairan mencapai 5,8 juta $\mathrm{km}$ dan garis pantai mencapai $81.000 \mathrm{~km}$, memiliki potensi besar dalam hal pengelolaan kekayaan laut dan salah satunya adalah kerang. Meningkatnya kebutuhan material beton memicu penambangan batu, yang merupakan material penyusun beton sebagai agregat kasar, sehingga menyebabkan turunnya jumlah sumber alam yang tersedia untuk keperluan konstruksi beton. Agregat kasar merupakan bahan penyusun beton yang paling dominan, maka untuk mengurangi penggunaan agregat kasar secara berlebihan perlu dilakukan penelitian dengan memanfaatkan cangkang kerang yang masih belum dimanfaatkan secara efisien sebagai subsitusi agregat kasar pada campuran beton.

Kerang darah termasuk family arcidae dan genus anadora. Kerang darah termasuk dalam kelas lamellibranchiata bersama dengan tiram, remis, dan sebangsanya. Berikut komposisi kimia dalam cangkang kerang darah :

Tabel 1. Komposisi Kimia Cangkang Kerang Darah

\begin{tabular}{cc}
\hline Komponen Kimia & Komposisi (\%) \\
\hline $\mathrm{CaO}$ & 66,70 \\
$\mathrm{SiO} 2$ & 7,88 \\
$\mathrm{Fe} 2 \mathrm{O} 3$ & 0,03 \\
$\mathrm{MgO}$ & 22,28 \\
$\mathrm{~A} 2 \mathrm{O} 3$ & 1,25 \\
$\mathrm{CaO}$ & 66,70 \\
\hline
\end{tabular}

Sumber : Tantra (2015).

Berdasarkan latar belakang diatas, maka permasalahan yang akan dibahas dalam penelitian ini adalah : (1) Bagaimana karateristik kuat tekan beton dengan cangkang kerang proporsi $0 \%, 5 \%, 10 \%, 15 \%$ dan $20 \%$ sebagai bahan substitusi agregat kasar dan bahan tambah superplasticizer dengan kadar 0,5\% pada campuran beton; (2) Berapakah persentase penambahan cangkang kerang sebagai bahan substitusi agregat kasar pada campuran beton agar menghasilkan kuat tekan beton yang optimal; dan (3) Bagaimanakah pengaruh penambahan superplasticizer pada beton cangkang kerang.

Bahan tambah (admixtures) adalah material yang ditambahkan dalam campuran beton selain semen, agregat, dan air. Bahan tambah ini diberikan segera sebelum atau pada saat proses pengadukan campuran beton dimulai. Secara umum fungsi dari bahan tambah adalah untuk menghasilkan beton yang lebih baik dari sisi pengerjaan, mutu maupun keekonomisannya. (Setiawan 2016). Beberapa penelitian terkait beton yang telah dilakukan yaitu berdasarkan hasil penelitian Andika \& Safarizki (2019) mengenai pemanfaatan cangkang pada kuat tekan beton dan diperoleh peningkatan $7 \mathrm{MPa}$ dalam campuran 5\% dan $3 \mathrm{MPa}$ dalam campuran 7,5\%. Berdasarkan hasil penelitian Amiwarti \& Mahipal (2019) tentang analisa pengaruh serbuk kaca dan abu terbang sebagai bahan pengganti alternatif terhadap kuat tekan beton diperoleh komposisi campuran yang 
optimal yaitu (Fc'- SK 15\% + AT 5\%) karena pada umur 28 hari nilai kuat tekan beton rata-ratanya sebesar $26,99 \mathrm{MPa}$ dengan pencapaian peningkatan kekuatan beton normal sebesar $5,55 \%$.

Menurut Amiruddin et al (2017) mengenai pemanfaatan limbah cangkang kerang dan limbah keramik sebagai pengganti agregat halus dan agregat kasar diperoleh penurunan kuat tekan beton sebesar 10,94\%,3,80\%, 23,60\% dan 25,88\% terhadap campuran beton normal. Penelitian terkait juga dilakukan oleh Latjemma et al (2020) tentang penggunaan kulit kerang sebagai agregat kasar memperoleh hasil campuran sebesar 5\% 25,92 MPa, campuran $10 \%$ sebesar 24,28 $\mathrm{MPa}$ dan 32,11 MPa, dan campuran $15 \%$ sebesar 23,02 $\mathrm{MPa}$ dan 34,92 MPa.

Dalam tinjauan literatur menurut Purnawirati \& Moi (2021) dalam hasil penelitian menggunakan bahan tambahan abu terbang dan superplasticizer sebesar 0,4\% dari berat semen memperoleh hasil kuat beton sebesar 14,34 MPa pada usia 28 hari dan 18,12 MPa pada usia 56 hari. Selain itu, Syariffudin et al (2021) juga melakukan penelitian tentang efek penggunaan serbuk cangkang keong sawah sebagai subtitusi parsial semen yang hanya dapat dilakukan dengan penambahan maksimal $5 \%$.

\section{METODE PENELITIAN}

Membuatan dan pengujian kuat tekan benda uji dilakukan di Laboratorium Uji Bahan Jurusan Teknik Sipil Politeknik Negeri Sriwijaya Palembang. Bahan pembuatan betonnya sebagai berikut: agregat kasar, agregat halus, semen Portland, cangkang kerang dan bahan tambah (superplasticizer)

Sedangkan peralatan yang digunakan antara lain : peralatan untuk sumber agregat (satu set saringan 0,075 mm sampai $38 \mathrm{~mm}$, density spoon, timbangan, kuas, satu set kerucut terpancung, bejana silinder, batang penumbuk, dan bejana rudolf); peralatan untuk sumber semen (satu set alat pendaduk, spatula, satu set alat vicat, dan tabung le chatelier); peralatan untuk sumber pengecoran (kotak aduk, alat pengaduk, bejana silinder, kotak spesi, density spoon, satu set kerucut abrams). Sampel yang digunakan adalah berbentuk silinder ukuran diameter $15 \mathrm{~cm}$ dan tinggi $30 \mathrm{~cm}$. Sampel di uji pada umur 7,14, dan 28 hari dengan jumlah sebanyak 54 sampel seperti pada tabel berikut :

Tabel 2. Sampel Penelitian

\begin{tabular}{|c|c|c|c|c|c|}
\hline \multirow{2}{*}{ No } & \multirow{2}{*}{ Kode Benda uji } & \multirow{2}{*}{$\begin{array}{c}\text { Cangkang } \\
\text { Kerang }(\%)\end{array}$} & \multicolumn{3}{|c|}{ Umur Pengujian (Hari) } \\
\hline & & & 7 & 14 & 28 \\
\hline 1 & $\mathrm{BN}$ & - & 3 & 3 & 3 \\
\hline 2 & BSP & - & 3 & 3 & 3 \\
\hline 3 & BK5\% SP $0,5 \%$ & 5 & 3 & 3 & 3 \\
\hline 4 & BK $10 \%$ SP $0,5 \%$ & 10 & 3 & 3 & 3 \\
\hline 5 & BK $15 \%$ SP $0,5 \%$ & 15 & 3 & 3 & 3 \\
\hline 6 & BK $20 \%$ SP $0,5 \%$ & 20 & 3 & 3 & 3 \\
\hline \multicolumn{3}{|c|}{ Total } & \multicolumn{3}{|c|}{54} \\
\hline
\end{tabular}

Keterangan :

BN : Beton Normal

BSP : Beton Superplasticizer

BK5\% SP0,5\% : Beton Cangkang Kerang 5\% superplasticizer 0,5\% 
BK10\% SP0,5\% : Beton Cangkang Kerang 10\% superplasticizer 0,5\%

BK15\% SP0,5\% : Beton Cangkang Kerang 15\% superplasticizer 0,5\%

BK20\% SP0,5\% : Beton Cangkang Kerang 20\% superplasticizer 0,5\%

\section{HASIL DAN PEMBAHASAN}

Perencanaan campuran beton ini menggunakan campuran beton sebagai berikut : (1) beton dengan kuat tekan fc' $25 \mathrm{MPa}$ untuk umur 28 hari; (2) digunakan semen Portland Batu Raja Tipe 1; (3) tinggi slump perencanaan diambil 60-180 mm; (4) besar butir agregat kasar maksimum adalah $40 \mathrm{~mm}$; (5) agregat halus yang digunakan zona 2; (6) faktor air semen maksimum 0,52; (7) jumlah cangkang kerang diambil dari persentase agregat kasar.

Tabel 3. Proporsi Campuran

\begin{tabular}{ccccc}
\hline No. & Semen $\left(\mathrm{Kg} / \mathrm{m}^{3}\right)$ & Air $\left(\mathrm{Kg} / \mathrm{m}^{3}\right)$ & $\begin{array}{c}\text { Agregat Kasar } \\
\left(\mathrm{Kg} / \mathrm{m}^{3}\right)\end{array}$ & $\begin{array}{c}\text { Agregat Halus } \\
\left(\mathrm{Kg} / \mathrm{m}^{3}\right)\end{array}$ \\
\hline 1 & 394,23 & 135,903 & 657,676 & 1087,201 \\
\hline
\end{tabular}

Tabel 4. Kuat Tekan Beton

\begin{tabular}{llccc}
\hline \multirow{2}{*}{ No } & \multirow{2}{*}{ Variasi Benda Uji } & \multicolumn{3}{c}{ Rata-rata Kuat Tekan Benda Uji } \\
& & 7 & 14 & 28 \\
\cline { 3 - 5 } & & 18,37 & 24,87 & 28,26 \\
1 & BN & 18,95 & 25,65 & 29,15 \\
2 & BSP & 20,00 & 27,08 & 30,78 \\
3 & BK 5\% SP 0,5\% & 17,41 & 23,57 & 26,78 \\
4 & BK 10\% SP 0,5\% & 16,06 & 21,74 & 24,71 \\
5 & BK 15\% SP 0,5\% & 14,91 & 20,18 & 22,93 \\
6 & BK 20\% SP 0,5\% & 14,9 & \\
\hline
\end{tabular}

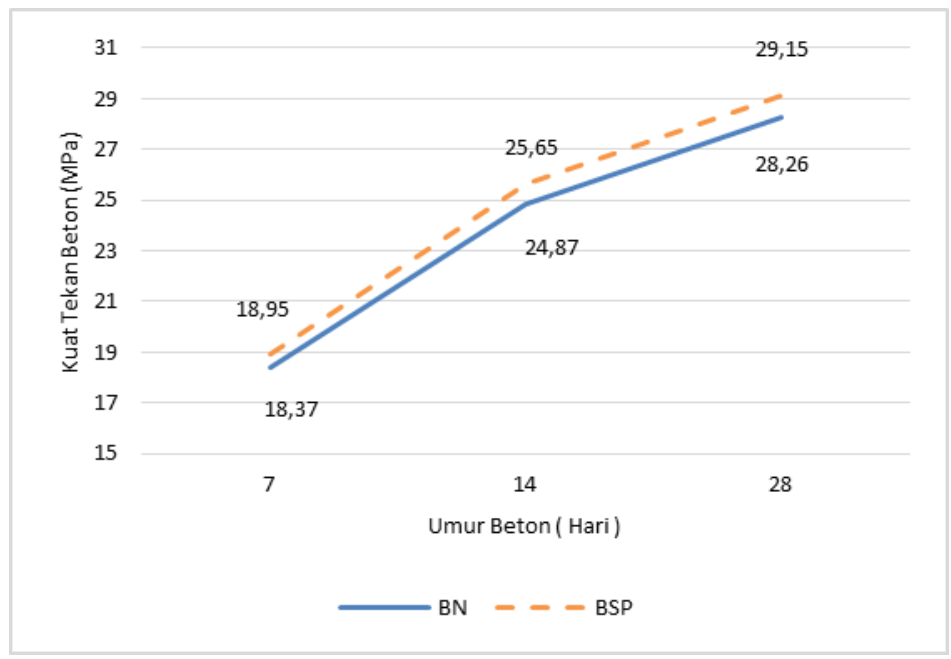

Gambar 1. Grafik Uji Kuat Tekan Beton Normal Dan Beton Superplasticizer 


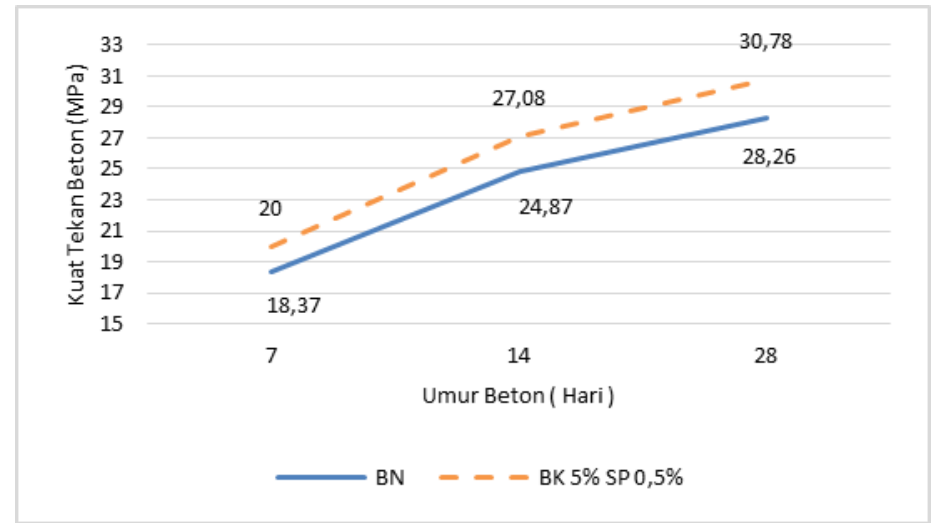

Gambar 2. Grafik Uji Kuat Tekan Beton Normal

Dan Cangkang Kerang 5\% Superplasticizer 0,5\%
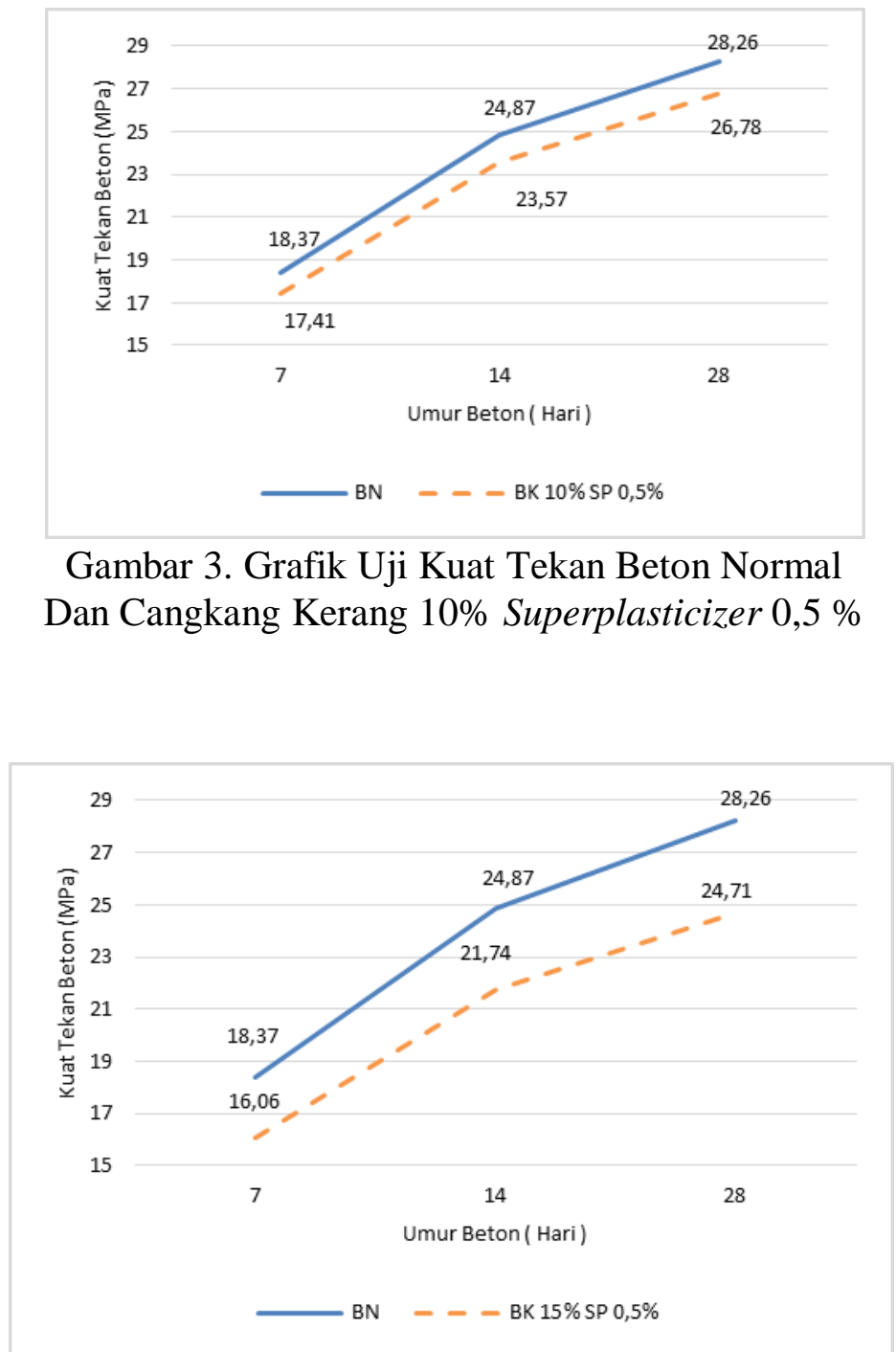

Gambar 4. Grafik Uji Kuat Tekan Beton Normal Dan Cangkang Kerang 15\% Superplasticizer 0,5\% 


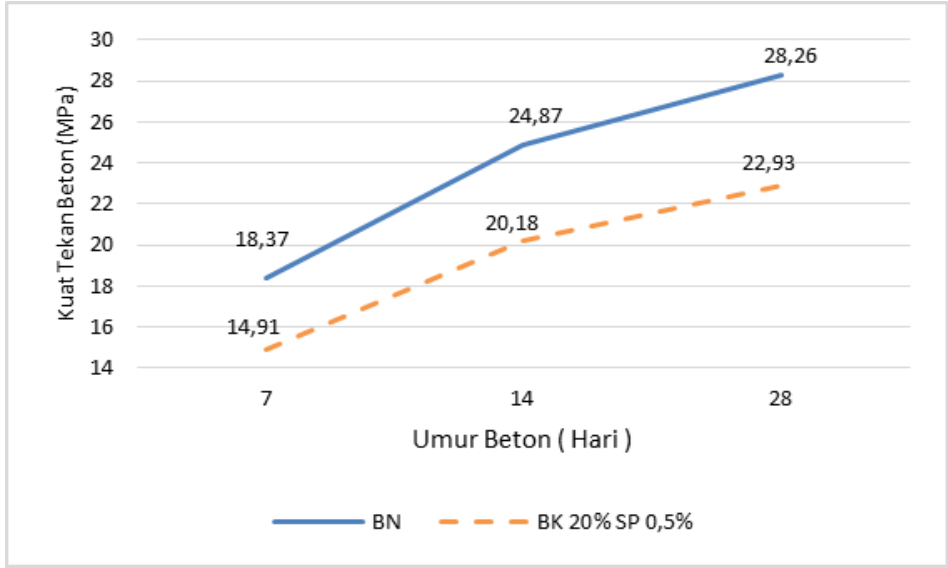

Gambar 5. Grafik Uji Kuat Tekan Beton Normal

Dan Cangkang Kerang 20\% Superplasticizer 0,5\%

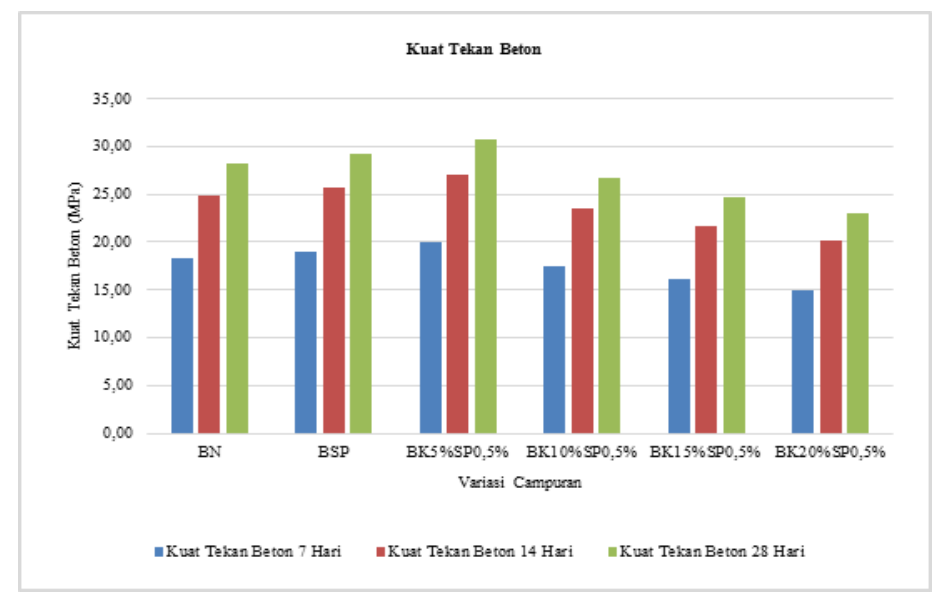

Gambar 6. Grafik Kuat Tekan Beton

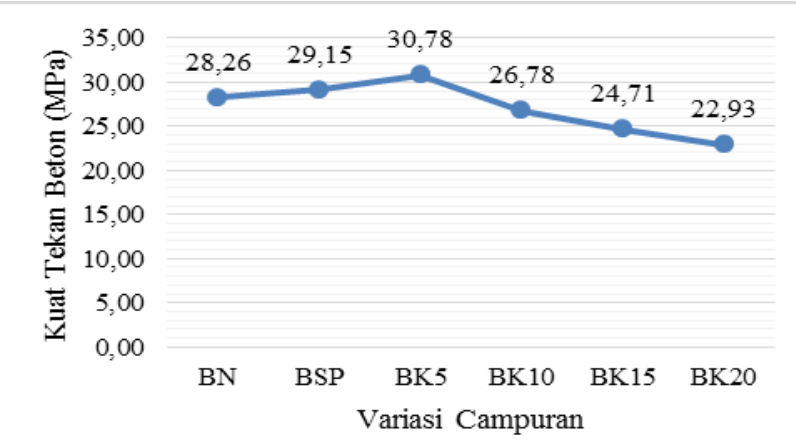

Gambar 7. Grafik Perbandingan Pengaruh Penambahan Cangkang Kerang Dan Superplasticizer 0,5\%

Dari grafik 7. dapat dilihat bahwa pada umur 28 hari, kuat tekan beton normal tanpa campuran kerang dan superplasticizer yaitu 28,26 $\mathrm{MPa}$, kuat tekan beton dengan penambahan superplasticizer $0,5 \%$ yaitu $29,15 \mathrm{MPa}$, dan kuat tekan beton dengan penambahan cangkang kerang $5 \% ; 10 \% ; 15$; dan 20\% dengan superplasticizer $0,5 \%$ yaitu 30,78 MPa; 26,78 MPa; 24,71 $\mathrm{MPa}$; dan 22,93 $\mathrm{MPa}$. Kuat tekan beton setelah ditambah cangkang kerang 5\% dengan superplasticizer $0,5 \%$ mengalami peningkatan yang cukup besar, tetapi setelah dilakukan penambahan cangkang kerang melebihi 
komposisi 5\%, kuat tekan beton mengalami penurunan yang cukup besar, sehingga komposisi penambahan cangkang kerang yang baik untuk campuran beton yaitu tidak melebihi $5 \%$.

\section{KESIMPULAN}

Dari hasil pengujian didapat kuat tekan beton normal dan beton superplasticizer $0,5 \%$ sebesar 28,26 MPa dan 29,15 MPa, sedangkan untuk kuat tekan beton cangkang kerang dengan komposisi 5\%, 10\%, 15\%, dan 20\% yang ditambah dengan superplasticizer 0,5 \% menghasilkan kuat tekan sebesar 30,78 $\mathrm{MPa}, 26,78 \mathrm{MPa}, 24,71 \mathrm{MPa}$, dan 22,93 MPa. Kuat tekan beton meningkat setelah ditambah bahan tambah superplasticizer $0,5 \%$ dan untuk penambahan cangkang kerang pada persentase 5\%, sedangkan untuk kuat tekan beton dengan penambahan cangkang kerang diatas 5\% mengalami penurunan. Sehingga karakteristik campuran beton yang baik untuk digunakan yaitu beton cangkang kerang dengan komposisi 5\% dengan bahan tambah superplasticizer sebanyak 0,5\%

\section{DAFTAR PUSTAKA}

Amiruddin, A. A., Alwi, A., \& Purbaningtyas, D. (2017). Pengaruh Pemanfaatan Limbah Cangkang Kerang dan Limbah Keramik sebagai Substitusi Agregat Halus dan Agregat Kasar Pada Beton Terhadap Kuat Tekan Beton. Jurnal Inersia, 9(1).

Amiwarti, A., \& Mahipal, M. (2019). Analisa Pengaruh Serbuk Kaca dan Abu Terbang Sebagai Bahan Pengganti Alternatif Terhadap Kuat Tekan Beton. Jurnal Deformasi, 4(1), 1-12.

Andika, R., \& Safarizki, H. A. (2019). Pemanfaatan Limbah Cangkang Kerang Dara (Anadara Granosa) Sebagai Bahan Tambah dan Komplemen Terhadap Kuat Tekan Beton Normal. MoDuluS: Media Komunikasi Dunia Ilmu Sipil, 1(1), 1-6.

Latjemma, S., Tahir, S., \& Haris, H. (2020). Studi Pemanfaatan Limbah Kulit Kerang Sebagai Agregat Kasar Pada Beton Normal. Siimo Engineering: Journal Teknik Sipil, 4(1), 29-39.

Mulyono, Tri, 2005, Teknologi Beton, Edisi kedua, Yogyakarta: Andi Yogyakarta.

Purnawirati, I. N., \& Moi, F. (2021). Penggunaan Variasi Abu Terbang dan Superplasticizer Dalam Pembuatan Beton Ringan Struktur. Jurnal Talenta Sipil, 4(1), 74-78.

Ridha'al Syariffudin, R., Manalip, H., \& Mondoringin, M. R. (2021). Pengaruh Penggunaan Serbuk Cangkang Keong Sawah Sebagai Substitusi Parsial Semen Terhadap Nilai Modulus Elastisitas. Jurnal Sipil Statik, 8(5).

Setiawan, Agus, 2016, Perencanaan Struktur Beton Bertulang, Jakarta: Penerbit Erlangga

Tantra, A. (2015). Pengaruh Komposisi dan Ukuran Makro Serbuk Kulit Kerang Darah (Anadora Granosa) Terhadap Komposit Epoksi-PS/Serbuk Kulit Kerang Darah (SKKD) Medan (Doctoral dissertation, Tesis Fakultas Teknik. Departemen Teknik Kimia USU). 